\title{
Summum Bonum na Rede: a conectividade é algo admirável?
}

\author{
Francisco José Paoliello Pimenta \\ Universidade Federal de Juiz de Fora \\ Dimas Tadeu de Lorena Filho \\ Universidade Federal de Juiz de Fora
}

\begin{abstract}
Resumo: Os resultados deste trabalho inserem-se nos esforços realizados no âmbito do Grupo de Pesquisa Comunicação e Tecnologias da UFJF, em linha dedicada ao tema Ciberativismo na Iberoamérica: do despertar em Chiapas aos movimentos urbanos em Barcelona e Madrid. Neste caso, buscou-se um aprofundamento de questões, a partir da Semiótica de Peirce, situadas na esfera da terceira hipótese da pesquisa, segundo a qual a organização em redes por parte dos ciberativistas iberoamericanos pode ampliar a autoconsciência de seus processos sígnicos, predispondo a mudanças de hábitos de sentimento, de ação e do pensamento.
\end{abstract}

Palavras-chave: Semiótica; Tecnologia Digital; Estética. 
Os resultados deste trabalho inserem-se nos esforços realizados no âmbito do Grupo de Pesquisa Comunicação e Tecnologias, em linha de investigação composta por professores e alunos de Mestrado e de Iniciação Científica da Faculdade de Comunicação da Universidade Federal de Juiz de Fora, reunido em torno do tema Ciberativismo na Iberoamérica: do despertar em Chiapas aos movimentos urbanos em Barcelona e Madrid. O objetivo geral desta pesquisa é o de analisar se a geração de Interpretantes mais ricos via representação da imersão parece apta a colaborar no sentido da construção de hábitos mentais de maior razoabilidade para o ciberativismo, ao atender aos requisitos de seu Summum Bonum estético, voltado para a democracia participativa e para um novo internacionalismo.

No caso específico desta comunicação, buscou-se um aprofundamento de questões, a partir da Semiótica Pragmaticista de Peirce, situadas na esfera da terceira hipótese da pesquisa, segundo a qual a organização em redes por parte dos ciberativistas iberoamericanos pode ampliar a autoconsciência de seus processos sígnicos, predispondo a mudanças de hábitos de sentimento, de ação e do pensamento.

\section{Summum Bonum: em busca de uma definição}

$\square$ Inicialmente, cabe definir com precisão o conceito de Summum Bonum, a partir da categorização de realidade proposta por Peirce em três esferas fenomenológicas, a Primeiridade, a Secundidade e a Terceiridade. A Primeiridade diz respeito às possibilidades, ao devir, ao indeterminado. A Secundidade diz respeito ao existencial, às relações de causa e conseqüência. Por fim, a Terceiridade engloba a categoria das leis, dos hábitos e do pensamento.

A partir dessas categorias, Peirce pôde, então, desenvolver sua teoria Semiótica por meio de tríades, entre as quais aquela que relaciona Representamen, Objeto e Interpretante. O Representamen é o Signo em si mesmo, independente do fato de vir a ser percebido por uma mente interpretadora, desencadeando uma semiose. Não se sabe como uma mente qualquer interpretará esse Signo, dentre a infinita gama de possibilidades que apresenta. Sequer se sabe se esse Signo virá a ser percebido. Portanto, como mera possibilidade, está ligado à Primeiridade. 
O Objeto é aquilo que o Signo intenta representar e que se coloca numa posição de radical autonomia em relação ao que quer que pensemos sobre ele, estando, portanto na dominância da Secundidade. Tal autonomia do Objeto em relação ao intérprete do Signo é um ponto crucial para se entender o pensamento de Peirce, já que conduz à sua filiação ao realismo escolástico, eliminando qualquer conjectura nominalista que considerasse o processo sígnico como produto exclusivo da mente humana. Peirce entende o pensamento como algo exterior a mentes particulares:

Não devemos adotar uma visão nominalista de Pensamento, como se fosse algo que o ser humano tivesse dentro da sua consciência. A consciência pode significar qualquer uma das três categorias. Mas se for significar Pensamento, ele está muito mais fora de nós, do que dentro. Nós estamos no Pensamento e não ele em nós. (CP 8.256, 257)

Não pretendemos, aqui, nos determos nesta questão, que conduziria à esfera da Metafísica, porém vale usá-la para ressaltar a importância do Objeto como algo que existe por si só, e que é independente da interpretação que lhe seja dada por uma mente qualquer.

A concepção do processo sígnico como tríade se completa com o Interpretante, que constitui a relação de representação estabelecida entre o Representamen e o Objeto, estando, assim, na chamada Terceiridade. Uma compreensão adequada deste conceito é fundamental para que se chegue ao que se quer dizer como Summum Bonum. Peirce dedica grande atenção ao estudo do Interpretante e à forma como ele pode influenciar futuras semioses:

Uma lei que nunca opera não tem existência positiva. Conseqüentemente, uma lei, que operou pela última vez, deixou de ser uma lei, exceto como uma mera fórmula vazia que pode ser conveniente permitir que se mantenha. Assim, afirmar [ou crer] que uma lei positivamente existe é afirmar [ou crer] que ela operará e, portanto, se referir ao futuro, mesmo que apenas de modo condicional.(CP 5.545)

Ora, fica claro, portanto, que uma lei, um padrão, ainda que adquirido ou identificado no presente, poderá vir a se associar a Signos semelhantes no futuro. O Pragmatismo está, portanto, relacionado ao estudo de como os Interpretantes afetam novas semioses. 
Para compreender os efeitos pragmáticos das cadeias Semióticas é importante atentar para uma, dentre as muitas possíveis e controversas classificações que Peirce reserva aos Interpretantes. Ele postula, nos seus Collected Papers, que o Interpretante pode ser Emocional, Energético ou Lógico, em referência direta às três categorias mencionadas acima. O Interpretante Emocional, como algo da esfera da Primeiridade, é apenas uma possibilidade inscrita no Signo, da esfera do sensível, ou seja, é uma potencialidade que o Signo está apto a produzir. Já o Interpretante Energético, num segundo momento, é aquele efeito efetivamente gerado pelo Signo e que permite a ocorrência dos processos de comunicação entre mentes singulares.

Em relação ao Interpretante Lógico, Peirce o identificou como aquela tendência a gerar o autocontrole, ou seja, um parâmetro através do qual a mente interpretadora passará então a se balizar em semioses futuras, consistindo, portanto, num hábito. Haveria, ainda, um Interpretante Lógico Último, que não poderia, entretanto, apesar do termo utilizado, ter um caráter terminativo face à concepção de semiose ilimitada. Daí, Peirce conclui que o Interpretante Lógico Último só poderia ser uma mudança de hábito. Assim, toda semiose tenderia, ainda que minimamente, a essa mudança que, tão logo ocorresse, tenderia para uma outra e, assim, ad infinitum.

A partir disso, é necessário compreender a relação entre o Pragmatismo e as Ciências Normativas, ou seja, a Lógica ou Semiótica, relativa à Terceiridade; a Ética, relativa à Secundidade e a Estética, relativa à Primeiridade. Sobre tal articulação entre essas ciências e o Pragmatismo diz Santaella:

Como uma doutrina lógica ou um método para determinar o significado dos conceitos intelectuais, o Pragmatismo aponta diretamente para a importância da ética. Um ano depois de ter postulado que a lógica está alicerçada na ética, Peirce postulou, em 1902, que a ética está alicerçada na estética e que a esta cabe a descoberta do ideal supremo, o Summum Bonum da vida humana. (SANTAELLA, 2004A, p. 79)

Portanto, a tarefa da Lógica de compreender os processos sígnicos mais complexos está ligada intimamente à Ética que, no sentido peirceano, diz respeito ao estudo da conformidade entre fins e uma determinada ação, ou seja, o porquê de se agir de tal ou qual forma. A articulação seguinte, entre Ética e Estética, é, então, o 
passo fundamental dado por Peirce, pois apresenta como motivo pelo qual se é levado a agir de determinado forma, o parâmetro que determina o que parece admirável (kalós) ou não, é justamente o Summum Bonum, sendo este um geral, ou, como o próprio autor coloca, “o ideal dos ideais”. É à Estética, que no sentido peirceano não tem ligação com o belo, que cabe a busca desse ideal supremo, em direção ao crescimento da razoabilidade coletiva. De acordo com Potter:

Os frutos que brotam do desejo de um indivíduo não devem se limitar aos seus próprios alvos, mas seus esforços devem contribuir para um resultado coletivo - o crescimento da razoabilidade no mundo. O significado de um conceito assim é julgado em termos de contribuição que as reações que ele evoca produzem para a realização da finalidade última do pensamento. A máxima pragmática passa a ser vista como o modo de se reconhecer a realidade dos objetos das idéias gerais na sua generalidade. (POTTER, 1997 apud SANTAELLA, 2004A, p.81)

\section{A conectividade: um kalós?}

A partir do exposto acima, lançamos, aqui, como hipótese, que o "ideal dos ideais", postulado por Peirce em sua Estética como propedêutica primeira para qualquer ação, poderia, na contemporaneidade, ser relacionado a uma qualidade que estaria na base do sentimento coletivo de crescente compartilhamento sígnico por meio da rede mundial de computadores e sua tecnologia digital. Neste sentido, atividades cada vez mais freqüentes no cotidiano ligadas à comunicação imediata, planetária, ubíqua, portátil e em rede podem servir para uma propícia anologia com o Summum Bonum.

Na relação entre comunicação e Summum Bonum, aqui proposta, interessa estabelecer, em primeiro lugar, se a este sentimento pode, de fato, ser atribuída a qualidade de admirável, na medida em que é sobre tal tipo de fenômeno que ações decisivas e pensamentos críticos encontrariam sua fundação, o que nos conduziria à relevância de tal formulação. O quer dizer que, caso isto ocorra, estarão dadas as condições para condutas cada vez mais adequadas ao contexto social, com crescente razoabilidade lógica, considerando-se que hábitos de conduta e de pensamento podem ser cultivados sobre hábitos de sentimento considerados admiráveis.

Peirce fundou a idéia de admirável na Estética para que este conceito não tenha compromissos com qualquer tipo de pensamento ou ação, e sim esteja 
associado a uma mera qualidade que seja adotada por uma coletividade sem nenhum motivo especial. A partir de tal formulação, seria possível considerar que o ato de se comunicar é algo desejável onde quer que existam possibilidades de trocas de informação, em vários campos da natureza, incluindo a esfera humana. A restrição à comunicação vem sendo utilizada, atualmente, como uma das piores formas de tortura na base norte-americana de Guantánamo, levando os prisioneiros ao suicídio, o que exemplifica de forma cabal o quanto é desejável pelo ser humano. Na nossa hipótese intervém, ainda, a idéia de que as tecnologias digitais em rede se articulam a tal ideal de comunicabilidade, em vista de sua característica de plataforma sígnica voltada para a ampliação de contatos, conduzindo a uma conexão crescente e harmônica com a comunidade e com o meio ambiente.

Sustentar tal construção teórica sobre o conceito de algo que é, por si só, admirável, sem que seja possível determinar por qual motivo, só é factível em vista do Realismo Escolástico sobre a qual Peirce se apóia, e seu anti-fundacionismo, que recusa seja o essencialmente necessário ou o absolutamente certo. Assim, a vagueza caracteriza este conceito, que, por pertencer à categoria da Primeiridade, não se encontra sequer na esfera da existência, embora possa ser real. Se não existe, nada pode ser oposto a ele, mesmo idéias de falta, incongruência, ou qualquer outra qualidade negativa, pois oposições são fenômenos da esfera da existência (CP. 5.132). Nas palavras do autor:

Mas, para apresentar a questão da estética em sua pureza, devemos eliminar dela não apenas todas as considerações acerca de esforço, mas todas as considerações sobre ação e reação, incluindo toda consideração acerca da nossa recepção do prazer, tudo, em síntese, que pertença à oposição entre ego e não-ego. Não temos em nossa língua uma palavra com a generalidade requisitada. O grego kalós, o francês beau apenas se aproximam, sem atingí-la exatamente na cabeça. "Fine" seria uma pobre substituta. Belo é mau, porque um modo de ser kalós depende essencialmente da qualidade ser nãobela. Talvez, contudo, a frase "o belo do não belo" não fosse ofensivo. Mas "beleza" é muito superficial ainda. Usando-se kalós, a questão da estética é: Qual é aquela qualidade que, na sua presença imediata, é kalós ? Desta questão, a ética deve depender, assim como a lógica deve depender da ética. A estética, portanto, embora eu a tenha negligenciado terrivelmente, aparece possivelmente como a primeira propedêutica indispensável para a lógica, e a lógica da estética constitui uma parte distinta da ciência lógica que não deve ser omitida (CP 2.199). 
Se não há nenhuma necessidade no Summum Bonum, como é possível que ele seja a base para a razoabilidade ? A saída que Peirce encontrou para estes e outros dilemas gerados pelo fato dos fenômenos da esfera da Primeiridade constituírem o fundamento de processos envolvendo as demais categorias, envolvendo a existência e o pensamento, foi se apoiar na idéia de Lume Naturale, a exemplo de Galileu. Para Peirce, deve existir alguma tendência natural que leve a um acordo entre estas idéias que se sugerem à mente e aquelas relacionadas a leis da natureza, ou seja, "é mais do que uma mera figura de linguagem dizer que a natureza fecunda a mente do homem com idéias que, quando se desenvolvem, parecem com seu gerador, a Natureza” (CP. 1.80-1, 5.591). Em outro ponto de seus Collected Papers, Peirce se refere ao Lume Naturale com as seguintes palavras:

Desta forma, considerações gerais relativas ao universo, considerações estritamente filosóficas, quase demonstram que se o universo se conforma, com algum grau de precisão, a certas leis altamente pervasivas, e se a mente humana tem se desenvolvido sob a influência destas leis, é de se esperar que ela deva ter uma luz natural, ou luz da natureza, ou insights instintivos, ou inclinação tendendo a fazê-la adivinhar estas leis acertadamente. Esta conclusão é confirmada quando descobrimos que todas as espécies animais são dotadas de inclinações similares. (CP 5.604)

\section{O Summum Bonum e a Rede}

A partir daí, é possível encontrar diversas aproximações com a hipótese de considerar a qualidade de sentimento de estar conectado em escala planetária pela rede digital como algo da esfera do admirável. Em "Navegar no Ciberespaço", por exemplo, Lucia Santaella propõe a existência de três tipos de "leitores" dos processos sígnicos contemporâneos, em ligação direta com as categorias de pensamento de Peirce (SANTAELLA, 2004B). Após descrever o tipo contemplativo, ligado à Terceiridade, e o movente, ligado à Secundidade, a autora apresenta o leitor ligado à Primeiridade com perfil imersivo, ou seja, aquele que navega o ciberespaço. Mais do que os outros, esse leitor não só entra em contato com o Signo, mas se confunde com ele, se sente parte do processo. Pode alterá-lo, ignorá-lo, reapreendê-lo.

Essa "liberdade" da mente interpretadora em relação ao Signo acaba por gerar uma possibilidade de sentimento, algo da esfera da Primeiridade, que pode implicar em compartilhamento. Isto é, tudo que está na rede, que é ali discutido ou publicado, parece ser propriedade de todos que a ela tem acesso. Não por acaso, as 
discussões a respeito de direitos autorais cresceram muito desde o surgimento da Internet. Mesmo a noção de indivíduo se fragmenta, perde seu sentido no ciberespaço. Percebe-se, portanto, que a Internet, como espaço aberto à Primeiridade, "habitat" do leitor imersivo, tende a "gerais". Tudo ali dá a impressão de ser coletivo e o resultado é justamente o sentimento de compartilhamento referido há pouco.

A possibilidade de compartilhar um sentimento coletivo por meio da rede aparece na proliferação de estruturas auto-organizativas na rede, como ocorre na enciclopédia digital Wikipedia. Nesse caso, o meio digital permite que usuários em diferentes locações construam textos de forma colaborativa, sem nenhum outro ganho além do sentimento de fazer parte de um empreendimento conjunto voltado para a informação em geral. Outros desenvolvimentos da tecnologia digital neste sentido são o movimento pelo software livre e o do copyleft. No primeiro exemplo, o sentimento de compartilhamento está na base da construção de programas que são continuamente alterados pelos usuários com o objetivo de melhorar o desempenho e de responder a novos desafios. Já em relação ao copyleft, a idéia é de facilitar o acesso a produtos, o qual se dá sem restrições significativas de uso, embora não chegue a ser algo tão livre como o domínio público.

Em todos estes casos, pode-se observar o extraordinário apelo exercido por esta possibilidade de compartilhamento propiciada pela tecnologia digital em rede, que pode ser medido pelo envolvimento de milhões de usuários em todo o planeta. As melhores perspectivas, contudo, parecem estar nos desenvolvimentos que incorporam o lúdico. Já a partir da obra seminal de Huizinga, Homo Ludens, ficou claro que o jogo tem um poder de congregar os seres, e, no caso dos humanos, muitas vezes sem um objetivo utilitário, “desligado de interesses materiais”, mas por sua qualidade de desconexão com as obrigações da vida cotidiana (HUIZINGA, 2005). Huizinga critica a tendência de profissionalização dos jogos exatamente por perderem a espontaneidade que lhes confere o caráter lúdico mais puro. Tal ausência de propósitos utilitários, por si só, já aproxima o lúdico do conceito de Summum Bonum, porém, quando aplicado à esfera da comunicação digital em rede tal relação se amplia consideravelmente. 
É o que acontece no caso dos jogos eletrônicos para múltiplos usuários em rede. Nesta convergência de tecnologias, surge, concomitantemente, uma variedade de fatores que conduzem à idéia de Summum Bonum tal como o definimos aqui, ou seja, como associado à qualidade de sentimento de ampla conectividade em larga escala. Os jogos, além de contarem com o lúdico, se articulam por meio da baixa definição de sua linguagem híbrida, envolvendo, além do verbal, códigos visuais, sonoros e gestuais, criando, assim, um ambiente propício para relações entre Signos e objetos com alto grau de indeterminação, com ressonâncias no Summum Bonum. Cores, formas e sons estimulariam este sentimento de compartilhamento por meio de representações com crescente semelhança com o mundo vivido independente dos aparatos tecnológicos.

Os jogos eletrônicos, principalmente quando oferecidos em plataformas multi-usuários em rede, 24 horas por dia, implicam no mais alto grau de imersão com os atuais equipamentos, querendo se dizer com isso, conforme Murray, ser possível a sensação de estarmos envolvidos por uma realidade que se apodera de toda a nossa atenção e de todo o nosso sistema sensorial” (MURRAY, 2003: 102). Colabora com esta possibilidade a sensação de agência, ou seja, "a capacidade gratificante de realizar ações significativas e ver os resultados de nossas decisões e escolhas" (MURRAY, 2003: 127). E, finalmente, os jogos se mostram especialmente aptos às transformações, que "trazem à tona nosso prazer pela variedade em si mesma” (MURRAY, 2003: 153). Estas três características, levantadas por Murray, além de darem contornos realistas às representações, estimulam similaridades entre os Signos e os Objetos, o que pode ampliar a sensação de conectividade que estaria, segundo a nossa hipótese, associada à idéia de Summum Bonum.

Outra plataforma que se aproxima da idéia de Summum Bonum, num grau ainda maior do que o atingido pelos jogos eletrônicos é o ambiente Second Life. Além de ter características dos jogos ligadas ao Summum Bonum, descritas acima, o Second Life, tal como o próprio nome intenta sugerir, permite que o usuário reproduza uma série de atividades de seu cotidiano na esfera digital, incluindo relacionamentos pessoais e institucionais. Atividades econômicas, incluindo compras com a moeda própria, o Linden, ou em moedas internacionais são enfatizadas, o que vem transformando a plataforma num ambiente com um impacto financeiro 
significativo e crescente. Nos interessa aqui, contudo, sua característica de ampliar as possibilidades de conectividade dos jogos na medida em que o ambiente recriado pode ser experimentado como ampliação de vínculos relacionados à vida concreta dos usuários, sem que se percam as vantagens do lúdico.

O fato do Second Life possibilitar trocas de informações em relação direta com a esfera existencial abre novas possibilidades de semelhanças entre Signos e Objetos, na medida em que, neste caso, a agência e a transformação não só articulam como ampliam aquilo que está sendo vivido fora da rede pelo usuário. Aqui não se trata de um jogo e, sim, da vida real. Portanto, há um compartilhamento entre Signo e Objeto em termos das possíveis qualidades de pensamento, ação e, principalmente, de sentimento frente à ampla gama de situações concretas que o ambiente está apto a reproduzir para seus participantes. Assim, a ampliação da conectividade permitida por tais aplicações da tecnologia de comunicações digitais em rede se dá numa escala nunca antes atingida e, caso concordemos que é algo da esfera do admirável, kalós, pode vir a constituir uma base para novos hábitos voltados para uma crescente razoabilidade, tal como propôs Peirce.

\section{Referências bibliográficas:}

HUIZINGA, J. Homo ludens: o jogo como elemento da cultura. São Paulo: Perspectiva, 2005.

\section{MURRAY, Janet. Hamlet no Holodeck: o futuro da narrativa no} ciberespaço. São Paulo: Itaú Cultural / Unesp, 2003.

PEIRCE, Charles Sanders. Collected Papers. 8 vols. Cambridge: Harvard University Press, (1931 - 1958).

SANTAELLA, Lucia. (2004A) "Contribuições do pragmatismo de Peirce para o avanço do conhecimento" in Revista de Filosofia, Curitiba, v.16, n.18, p.75-86, jan/jun.

. (2004B) Navegar no Ciberespaço. SP: Paulus.

WIKIPEDIA. < http://www.wikipedia.org > acesso em 10/06/2005 